Article

\title{
From the Point Cloud to BIM Methodology for the Ideal Reconstruction of a Lost Bastion of the Cáceres Wall
}

\author{
Pablo Alejandro Cruz Franco ${ }^{1, *(1)}$, Adela Rueda Márquez de la Plata ${ }^{2, *(1)}$ and Jesús Cruz Franco ${ }^{3}$ \\ 1 School of Polytechnic, University of Extremadura, 10003 Cáceres, Spain \\ 2 Graphic Expression Department, School of Polytechnic, University of Extremadura, 10003 Cáceres, Spain \\ 3 Panta Rhei Desarrollo S.L., 10003 Cáceres, Spain; jcruzfranco@gmail.com \\ * Correspondence: pablocruzfranco@unex.es (P.A.C.F.); adelarm@unex.es (A.R.M.d.1.P.); Tel.: +34-927257195
}

Received: 20 July 2020; Accepted: 15 September 2020; Published: 22 September 2020

\begin{abstract}
Thanks to the use of non-invasive techniques and remote sensing in a 19th century building, it was possible to demonstrate that said building is a lost part of the Cáceres wall. This wall was believed to maintain the straight line from a known section, but remote sensing makes it clear that at that point the wall makes a break creating a door of which there was no record. Once this premise was confirmed, an ideal reconstruction hypothesis was developed. For this, the work base was taken on the data collected in an exhaustive data collection process, which launched millions of control points and facilitated in theorizing the original state of this lost section. The HBIM methodology greatly facilitated the process, and will allow for possible modifications with an IFC file as advances are made in that area. Finally, the research proposes an architectural project path that takes into account the data obtained remotely, and that achieves the inclusion of this part of the city in cultural interest and, of course, in a protected and cataloged area.
\end{abstract}

Keywords: laser scanner; georadar; BIM; cultural heritage; virtual reconstruction; Cáceres; Spain

\section{Introduction}

Locating and recovering the hidden heritage of cities requires a new look, as it is about changing established knowledge. This new look is provided by new technologies that allow for taking more precise data from the areas to be studied. In turn, this data collection allows for the reconstruction and modeling of these areas and for the comprehensive study of the sites and their monuments from a new perspective.

In this article, we present the application of multi-scaled images through the study of a practical case consisting of the location of a hidden section of a 12th century wall. This section was not documented in the historical sources nor cataloged in the current planning instruments, as it remained hidden among constructions that had been attached to it over time, and it was thought to have disappeared because it was not accessible physically.

This type of intervention has a great impact on the valuation and conservation of cultural heritage as it allows for a non-invasive way to have a comprehensive view of the monuments, helping to locate and study remains that are difficult to access, and as a result to catalogue and preserve them.

The methodology applied in this research work does not represent a great advance in itself with respect to the current state of the art, but the sciences applied during this method do represent a great innovation; that is, the technical and human equipment necessary to "unearth" the remains of the 12th century wall that was forgotten for centuries need to be very complex to handle.

Here, the human team was led by two architects and an economist (which in itself is a great novelty in the application of the BIM method); from there, we worked with an archaeologist, a technical 
architect, a civil engineer, a public works engineer, and a historian. We focused on seven very different scientific branches (without having support technicians and students) that converge in a very specific point in the city. To successfully carry out each part, a workflow and a scientific method were proposed, which represent the great contribution of this research to the methodological field. Each of the professions that intervened in the process used their most related methods, and it was through the BIM method that the results were overlapped and countered until reaching the conclusion of the exact place and the real trace that the wall had been "lost"in the city, as well as where to seek, protect, and prevent the discovery of historically highly relevant remains.

This text summarizes all of the actions carried out for the virtual reconstruction of the lost canvas of the wall of the historic city of Cáceres [1-3], a World Heritage City. For this, both preliminary studies (architectural, archeological, historical, etc.) and works executed with the first results on the study of the immediate surroundings of this section of the Caceres fence served to demonstrate the main hypothesis, namely the existence of a lost door of access to the city at this exact point in the wall. For this, exhaustive data and work were taken with remote sensing. In Figure 1, we can see the area of action within the intramural enclosure of the historic center of Cáceres, and in Figure 2 you can see the starting path of the wall at that particular point.

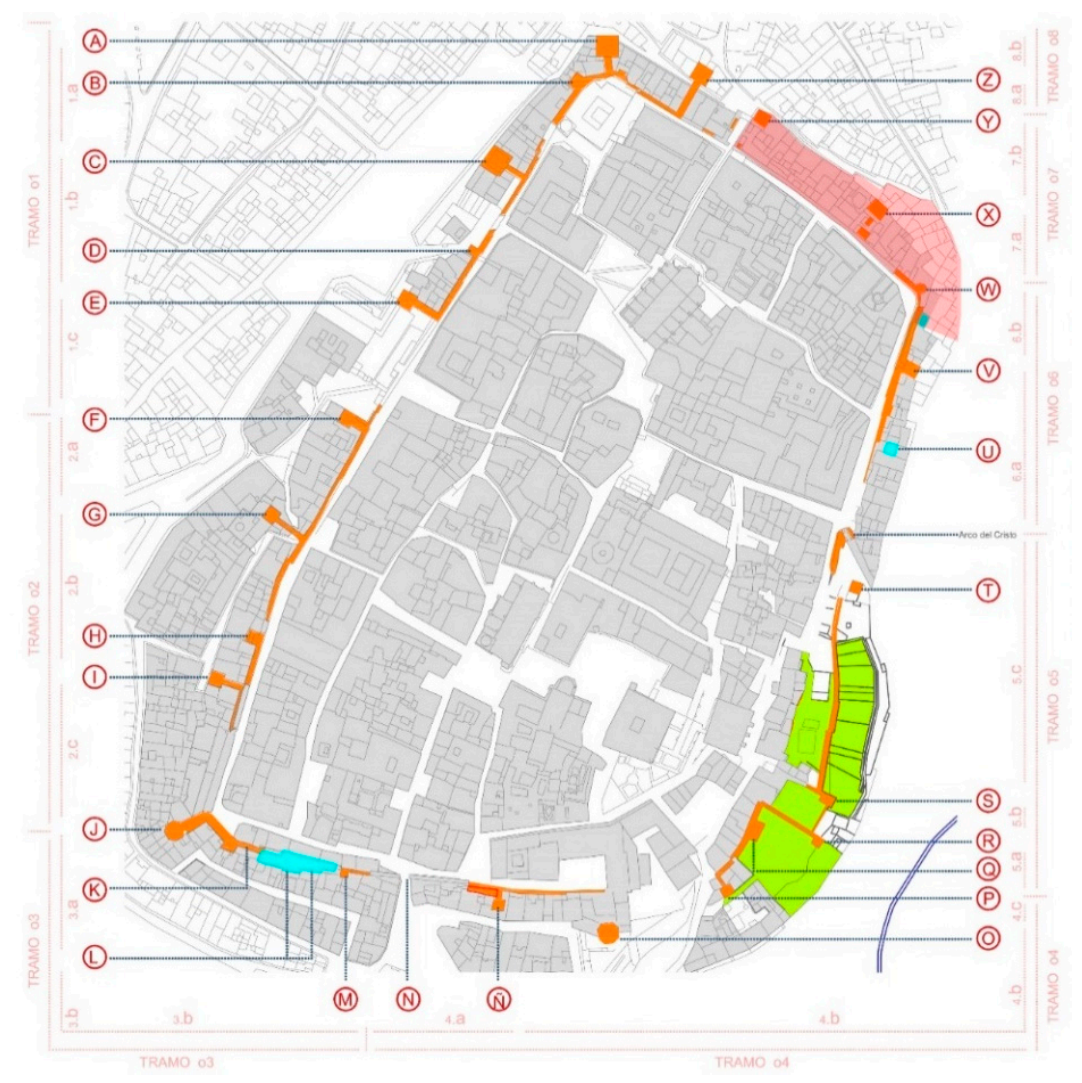

Figure 1. Location map of the intervention. A-garbage tower; B-Spain arch street tower; C-Bujaco tower; D-pulpit tower; E-Yerba tower; F-oven tower; G-Postigo tower of Santa Ana; $\mathrm{H}$-tower of Calle Adarve del Padre Rosalío; I-Aver tower; J-octagonal tower; K-tower for private use; L-hidden towers (historically located); $\mathrm{M}$-Cornudillas Street tower; $\mathrm{N}$-Mérida gate tower; N-Torremochada street tower; O-Torre mochadi; P-Hernando Pizarro street tower; Q-Covacha tower; $\mathrm{R}$-tower of the cisterns; S-water well tower; $\mathrm{T}$-river tower; $\mathrm{U}$-southern tower of Caleros Street; $\mathrm{V}$-Caleros tower; $\mathrm{W}$-round tower; $\mathrm{X}$-air tower; $\mathrm{Y}$-relief tower; $\mathrm{Z}$-king's tower. 


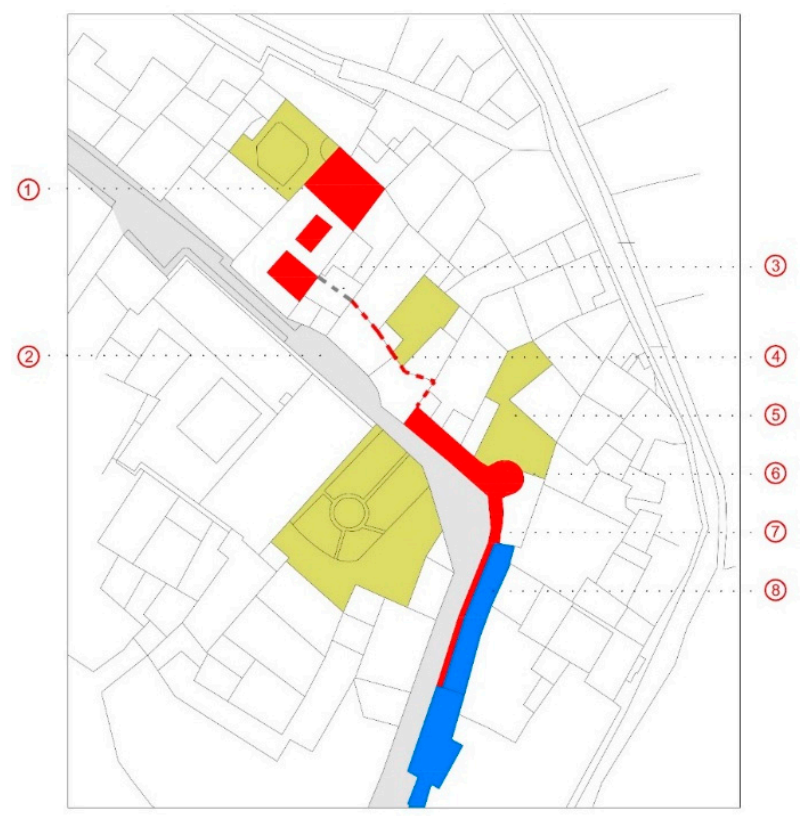

Figure 2. Identification of archaeological elements of the fence from the studies carried out in the area. 1-air tower; 2-Adarve del Cristo; 3-supposed layout of the wall based on the hypothesis; 4 -wall canvas hypothesis; 5-patios; 6-Ochavada tower; 7—conserved wall plot; 8-preserved antemural shape.

Throughout the document are images based on the work of the team that are the result of an exhaustive analysis of the environment of the area of enquiry. A precise laser scanner and photogrammetry survey was developed, which after its subsequent processing seemed to indicate geometric traces of the old wall.

With these traces, the precise knowledge of the geometry and especially of the topography (unknown until now), along with a thorough analysis by the multidisciplinary team, we use the following images to propose the hypotheses for how this section of the wall could be formed.

The rigorous work done here guaranteed that these documents had a centimeter accuracy, precision that, until now, has not existed in any document made and published on the intramural city of Cáceres or on its monumental area, or on any of its most influential palaces at an international level. The methodology will serve to guide and support protocolizing the documentary update that a World Heritage City needs (as it was named by UNESCO in 1986) and that is required by the new international standards of documentation.

\section{Hypotheses and Objectives}

The investigation into and the need for new technologies began with the architectural rehabilitation of a small building located in the street of Adarve del Cristo, which, even in its small dimensions, was in need of a careful and complete restoration project. Its location, following a visible canvas of the Arab wall and being perfectly documented, along with the random observation that part of the walls of the houses seemed to indicate that they could have been part of it, inclined the team, promoter, and architects towards a conceptually and methodologically different heritage "recovery" project. At this point, the research team specified the implementation of new technologies such as laser scanning and photogrammetry in order to understand the environment and the walled area in its most complex and least studied section.

Chance - the existence of reasonable doubt that a popular house of the nineteenth century was actually modifying the last layer of a living architecture that was an original space of the thirteenth century-gave way to the need for the valuation of the space in time and context in the search for memory and authenticity. 
This is how, from the beginning, the research process did not follow a classic linear flow (study-know-hypothesize), but instead chose a more open process. In this process, at each stage, we tried to obtain greater knowledge of the property and its relationship with the city in order to incorporate it into the project. The flow went from being linear to being iterative and incremental (research—understand—know—document, to re-investigate—understand—know—document, and so on as the project was developed).

This approach introduced two objectives for the team-first, to define the concept of authenticity so as to apply a consistent methodology [4-9], and second, to document the conceptual change that was the confirmation of the first hypothesis in changing the layout of the wall in this section. Hence, the use of photogrammetry, virtual reality, and centimetric data collection resolved both aspects when combined with data output treated with new BIM and HBIM methodologies, which valued what was discovered and updated the obsolete graphics that were in use until now [10-14].

At this point, the concept of objective rehabilitation was introduced, given that the project was articulated around the SSCM Method of Monumental Restoration of the Architectural Heritage Service of the Diputación de Barcelona [15], understanding that this methodology guaranteed the most valuable heritage and social results. Figures 3 and 4 show how the defensive wall was invaded for the new necessities of the city, making it disappear to the naked eye.
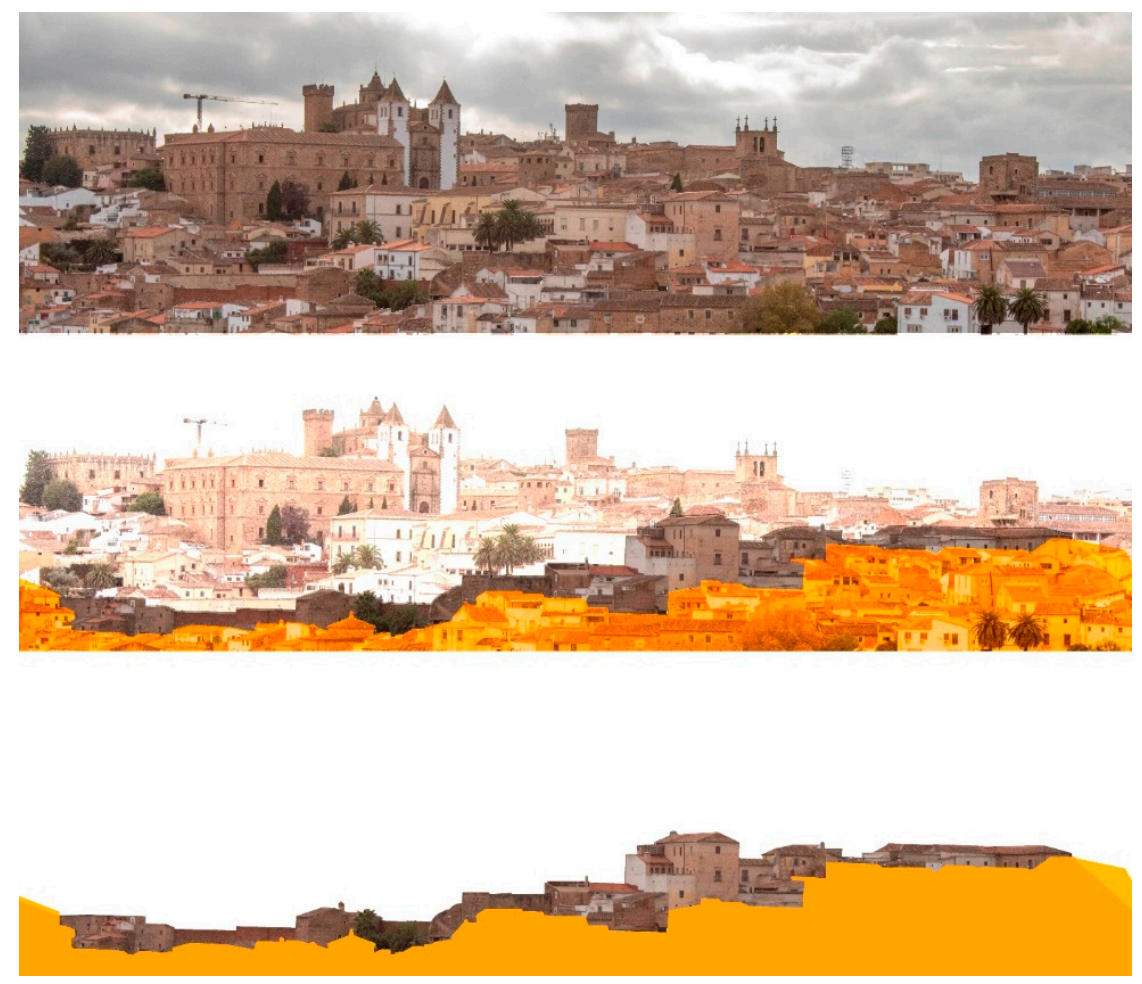

Figure 3. Location of the intervention within the defensive line currently absorbed by existing buildings. View from the Cerro de la Butrera.

Finally, to frame the hypothesis and the objectives of the project, and to highlight that the entire project process was developed under strict collaborative BIM methodology, not only the software was framed in this method, but instead the entire project was carried out within a common data environment-a common server of the university was created that facilitated the collaborative process of the research work, respecting all of the steps and protocols of the BIM project management.

To understand the global methodological implementation, we first needed to take into account that the objective restoration in the rehabilitation as well as the architectural authenticity needed to prevail; namely the essential values with which the monument was conceived are considered over the 
originality of the materials. In this sense, a space is more authentic the closer it is to that which was conceived by the author, regardless of whether the constructive elements are the originals or others by which they have been replaced.

Hence, the virtual reconstruction of the source architecture was crucial for obtaining valid results.
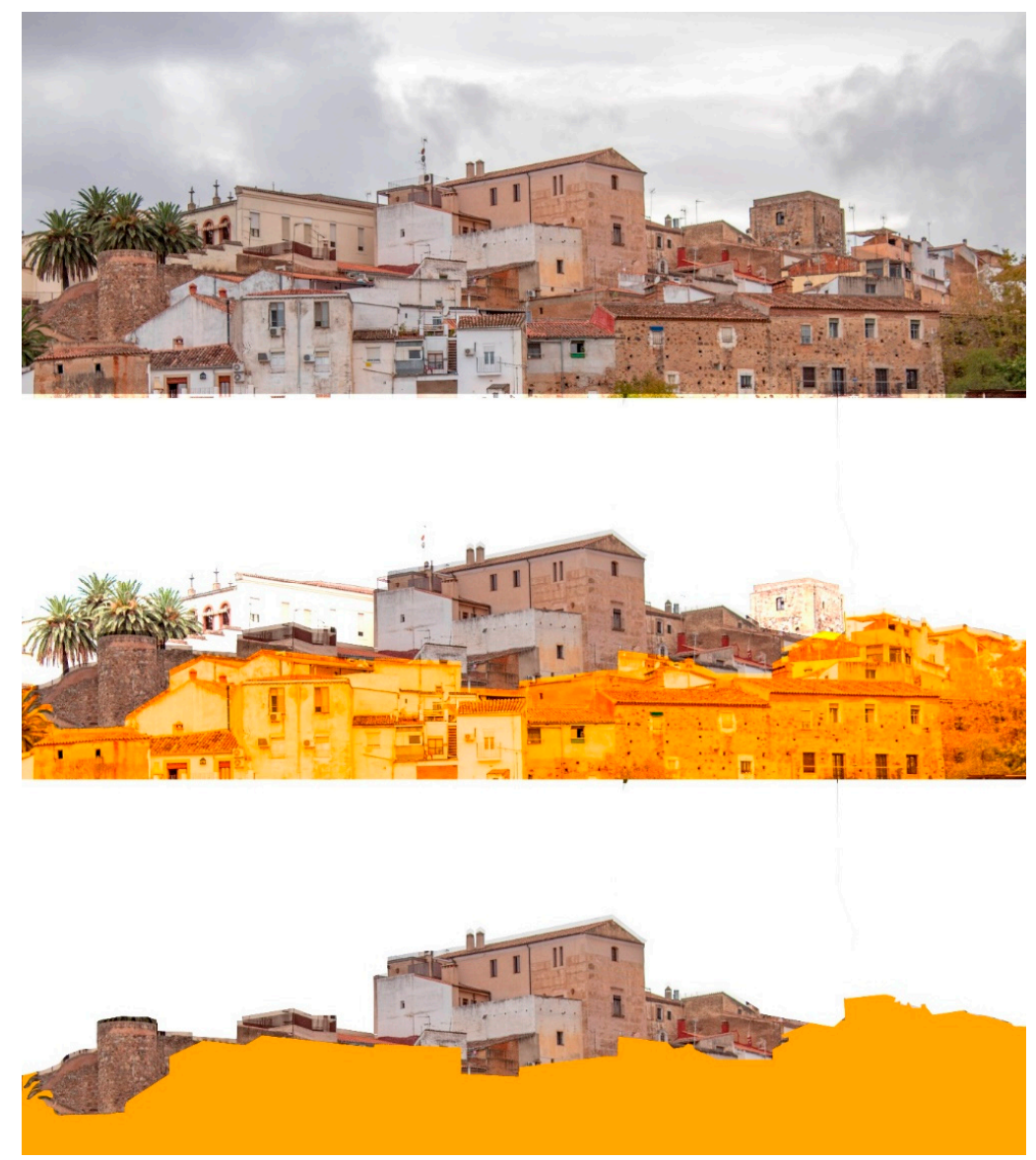

Figure 4. Location of the intervention within the defensive line currently absorbed by the existing buildings. View from the surroundings of the Rivera del Marco.

\section{Methodology}

Finding the essential values of the working environment was complex for two reasons. The first was that the original construction was unknown, although there were elements in the house that visually pointed to a relationship with the wall, these were neither cataloged nor studied. The second was, as with many monuments, that the "current" state was the result of an evolutionary process over centuries, which had been adding constructive elements without a continuity solution. Therefore, at first glance, discerning between what was contingent and essential was not obvious.

This situation demanded a methodology that allowed for a first phase of valuation of the construction, its medium, and the immediate environment, and a second exclusive phase of the property that would draw the old door of the wall. Throughout, we ensured that a professional and interdisciplinary nature of the studies undertaken, as was done through the methodological approach of objective restoration that the project drafting team used as a design guide. In Figure 5, we can appreciate the workflow used during the research. 


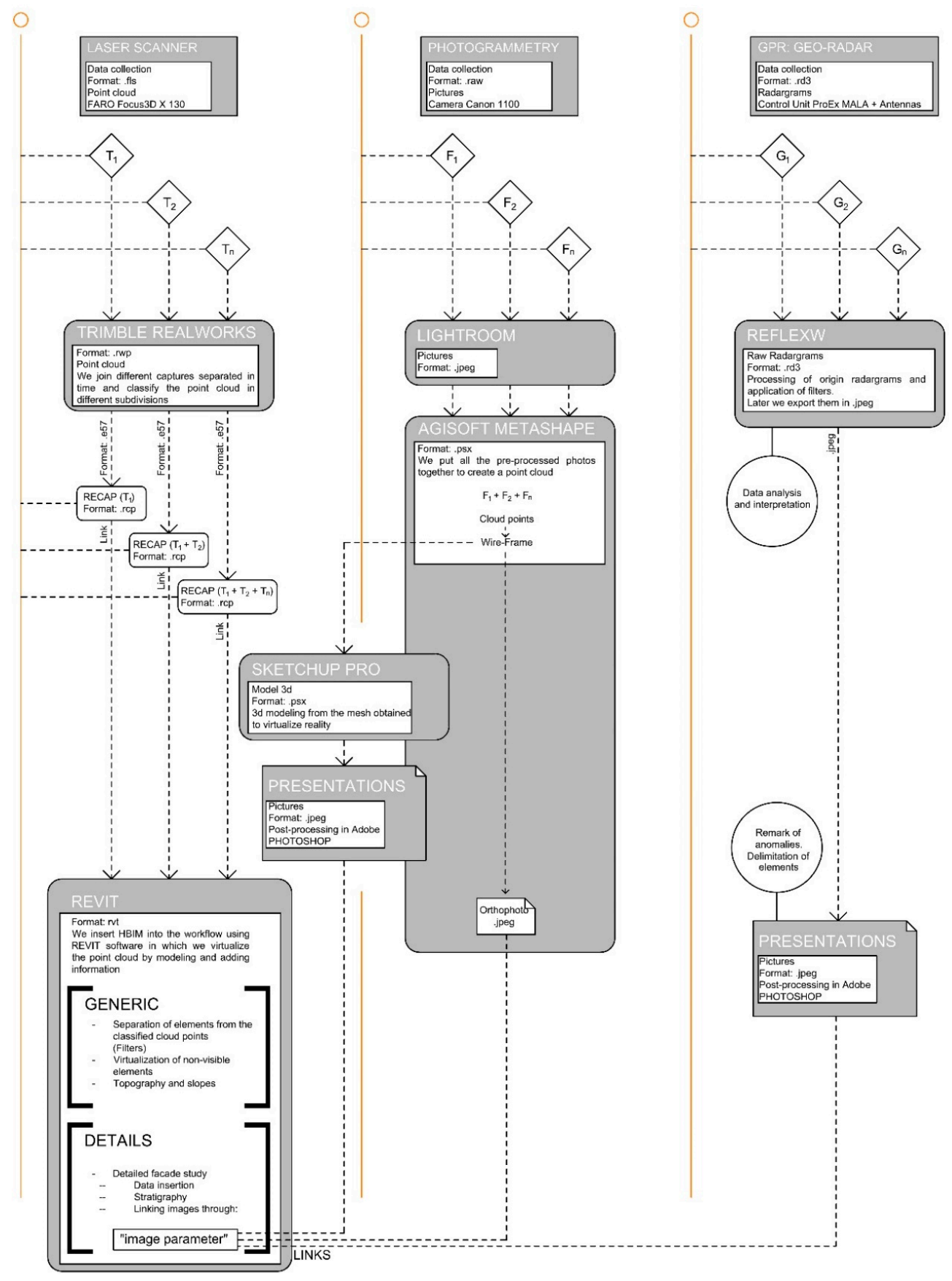

Figure 5. This figure shows the workflow used.

\section{First Phase-The Environment}

The historic city of Cáceres sits on an elevated site that, at this point, creates a very steep slope; the current homes and buildings need to adapt to the land, leaving patios, corralas, and terraces at various heights, making evaluation difficult. The understanding of this space was only able to be done through an exhaustive methodical work consisting of geometrically checking the different heights of each one of the constructions together with the street in order to elaborate on the concordances and similarities, which confirmed the initial theory of the continuity of the wall.

To do this, a global point cloud was created. Each of the techniques used had their own cloud of points as a partial conclusion. To create one that could provide us with the final conclusions and the overall vision, the point clouds resulting from the laser scanner survey and the photogrammetric 
survey needed to superimposed. In this way, the cloud that was obtained would have the data and metadata associated with each point, depending on the technique with which it was taken, and would be unique and global for all research work [16,17].

First, with the laser scanner, a massive capture of points was obtained with which the cartographic base was created, which served as the basis for the subsequent implementation of the rest of the techniques. In Figure 6, we can see the point cloud taken with a laser scanner from the interior of one of the referenced buildings of the general mesh of the project.

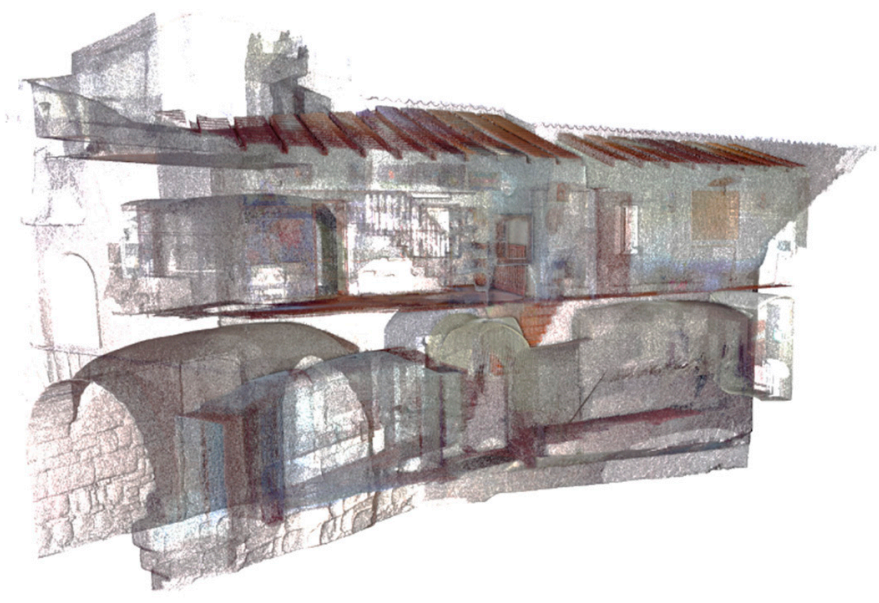

Figure 6. The methodology developed to elaborate the general mesh of the project allows for including the survey of the interior point cloud of the palaces and buildings they are carried out.

The scanner used was the FARO FOCUS 3D X330 model, but as the volume of the shots was very large and the weather was frequently changing, it took several different days to complete the selected volume and area, as can be seen in Figures 7 and 8 . To place the spheres, we started from the premise that we could carry out subsequent campaigns in order to complete the three-dimensional model. These campaigns would mainly be motivated by the need for accessing the interior of properties, which would broaden our knowledge of the area and the quality of our work, besides generating a dynamic and lively tool that could be updated a speed that matched the city.

For this, the procedure followed to carry out the survey of our three-dimensional model consisted of scans separated by $30 \mathrm{~m}$ at most. These scans were supported by a particularly dense mesh of spheres to allow for referencing in the future if necessary.

To locate this position of the spheres in future research work in the same area, metal spikes were embedded into the pavement that allowed us to reconstruct the physical mesh of the spheres, either partially or completely. These points were also positioned using centimeter GPS and were referenced on a city map to facilitate their location as if they were topographic nails.

The very high density of this mesh responded to two needs, namely: the first, to have emergency points to resort to in the event that, as a result of works or vicissitudes in the pavement, one or more control/link points were lost, deteriorated, or moved to their original position. The second, the need or premise was to have in a simple and easy way for the necessary references to interconnect the different models, that is, with a single scan from the door of the property that we would incorporate into our model in the future, we would already have the information necessary to connect it to the general project.

In addition, this mesh allowed us to have a series of control/link points that served to connect different three-dimensional models (point cloud, mesh models, textures, etc.), present or future, taken with other complementary techniques, such as photogrammetry using UAV or SLR, to part of the TLS model. 

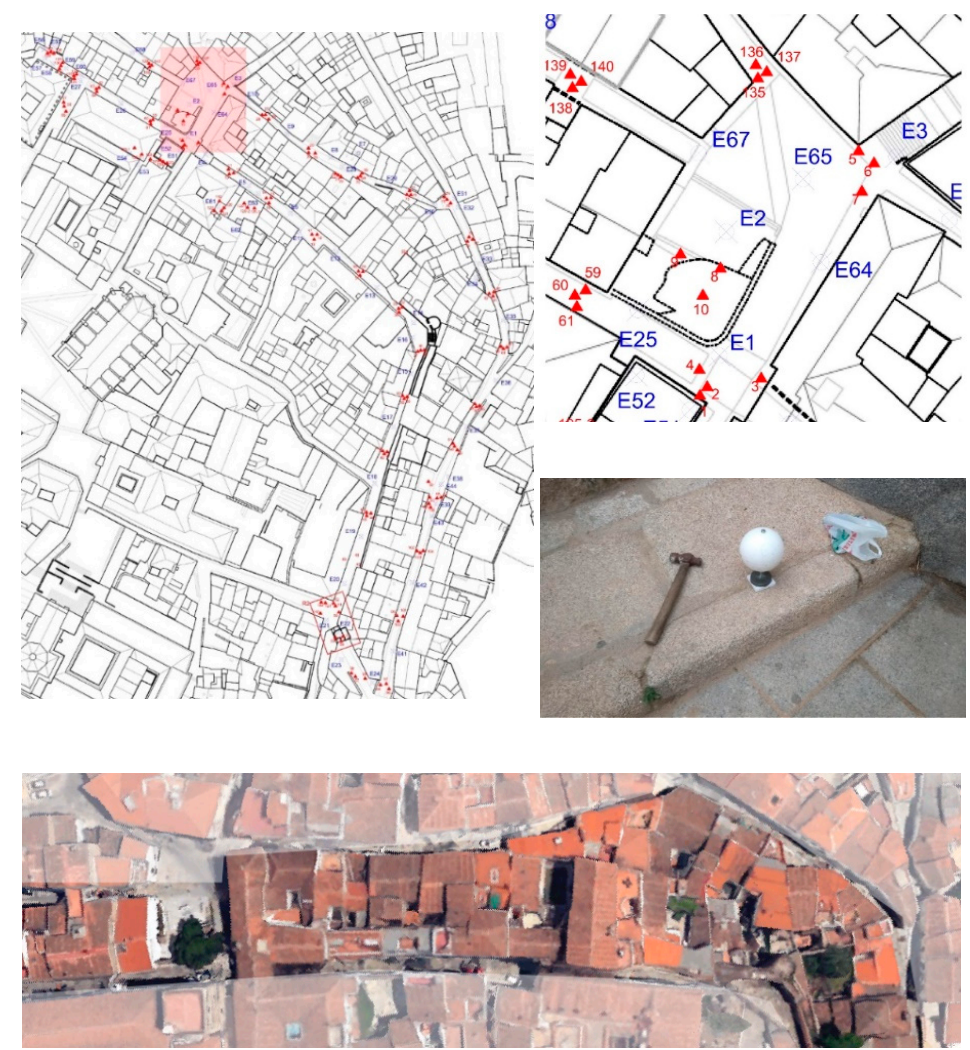

Figure 7. Location and detail of the spheres along a segment of the studied area.
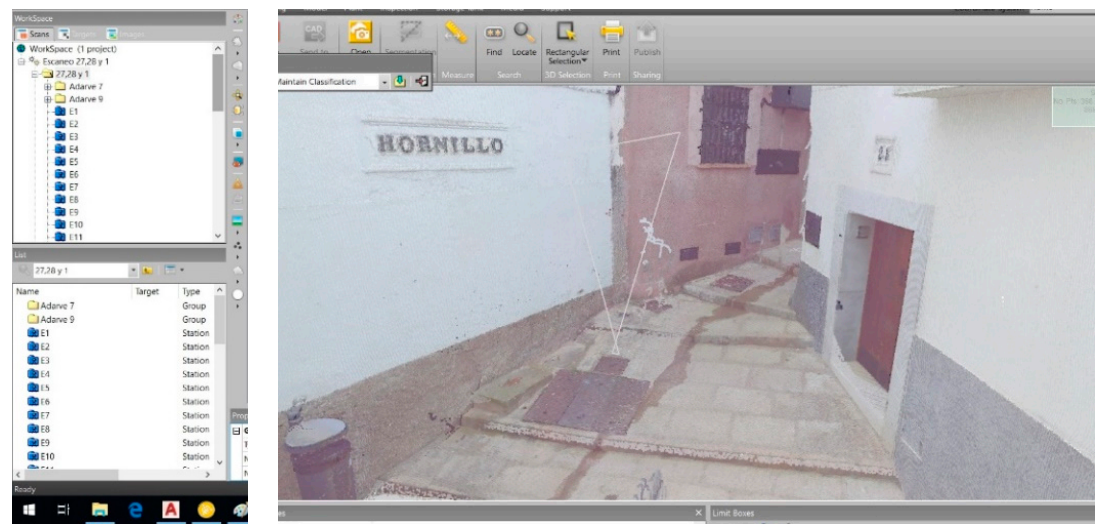

Figure 8. Image of work done using Agisoft: triangulation of overlapping photos in the program.

After the fieldwork, the scans were processed with the Trimble RealWorks [18] software-108 scans were needed, giving a complete model of 214 million points. One of the work-views can be seen in Figure 9.

In addition to this, an exhaustive photogrammetry work was performed [19]. The Canon 1300D camera was used for this in the traditional way. In total, 2148 photographs were taken from different points and altitudes that complemented the areas where the laser scanner could not reach, due to the intricacies of the buildings. Specialized software was used for image processing, in the first instance Adobe Photoshop CC 2018 was used for small touch-ups of shadow, light, contrast, or color correction, so as to avoid jumps and large cuts in the final images.

Then, the Agisoft Metashape [20] program was used on the photographs with which the point clouds were obtained, and the model was scaled to 1:1 and referenced to the general scanner model 
contributing to the final model—more than a million points filled in the gaps left by laser, as can be seen in Figures 8 and 9.

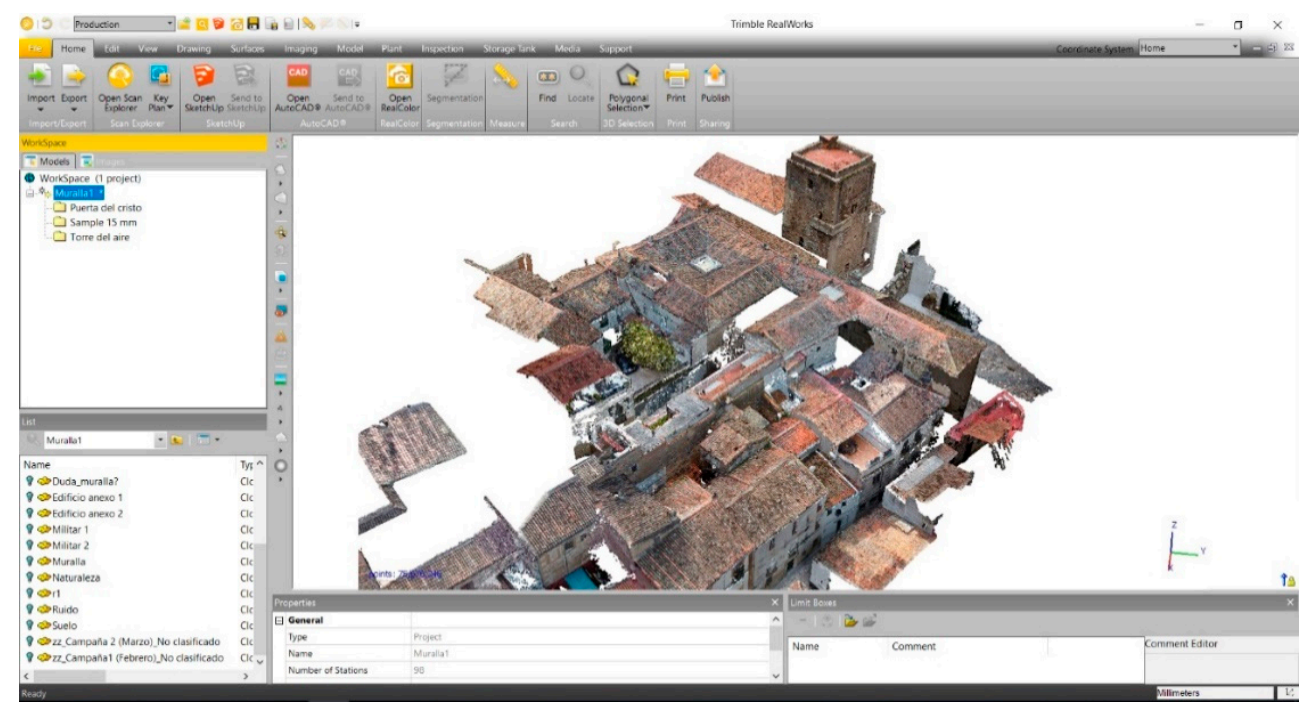

Figure 9. Classification of the point cloud with Trimble RealWorks software.

\section{Second Phase-The Building}

This phase focused the investigation in the exact area where a bastion or entrance to the wall was presupposed, the real fact is that a break in the layout of the same area had been demonstrated, and it was necessary to confirm at this point and in this property the real materiality of the vertical walls and if their discontinuities explained or drew how the wall had been at its most blurred point at the moment.

A three-dimensional study of discontinuities and inconsistencies in both walls and floors was proposed, and different visible and non-visible layers of the thicknesses of the walls and the different changes in the heights of the walls were studied, in addition to how far the walls reached, and whether or not the mother rock emerged and at what distance. All this was done in order to date and make a reconstruction of what could be the fence, and how it was modified over time until it became a popular home today.

For this, precise photogrammetric sections of each vertical wall were made in order to study the continuity or not of each stratum in the wall [21,22]. Figure 10 is an example of one of this section.

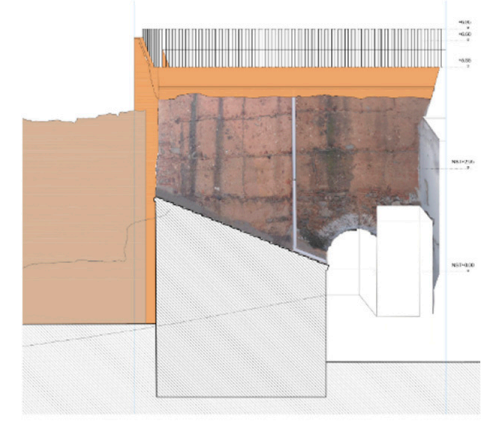

(a)

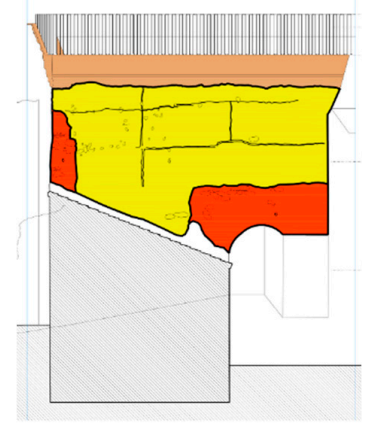

(b)

Figure 10. (a) Orthophoto of the rear façade. (b) Classification by elements. 
In addition, a GPR study was carried out in order to refine the thicknesses of these layers and to control what was happening inside the wall-we were looking for holes and gaps that also explained the construction model followed for each material [23-25]. One of these radargramas it is shown in Figure 11, where the discontinuities in the wall can be seen.

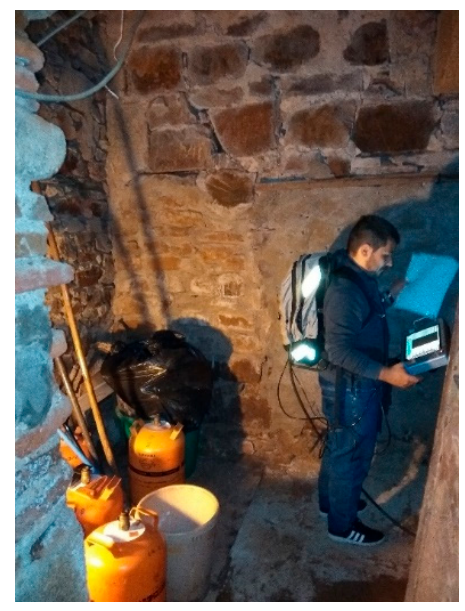

(a)

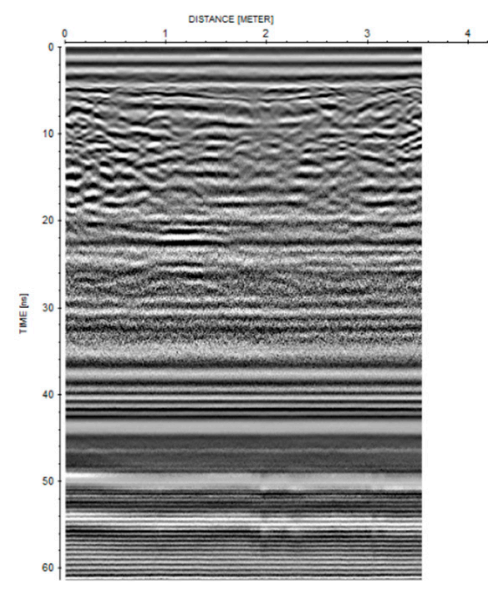

(b)

Figure 11. (a) Field work photography; (b) radargrama obtained in one of the walls with when attempting to obtain the thicknesses of wall and hidden cavities.

Thanks to this methodology, it was possible to detail a sharp change of material to $2.4 \mathrm{~m}$, which is understood as the original rock or foundation of the wall at this point in the city, something that, until now, had not been known, and that greatly facilitates our the understanding of this unique element cataloged and protected within this context [26,27].

\section{Conclusions}

First, it should be noted that one of the clear objectives of this study was met, which was the protocolization of a useful method for the study and analysis of complex and blurred constructions, namely those that do not have an obvious limit and that are gradually integrated into the urban plot and the topography, thus becoming lost in one another, but which, in turn, have forged this urban plot and its surroundings over centuries [28,29].

Then, the detailed and non-invasive analysis of the urban settlement of the wall and its surroundings reflected data of great interest that, until now, remained hidden, either because they were not visible to the naked eye or because they did not have the visible spatial-dimensional relationship between different elements that, having them raised with clouds of points, it has been possible to understand their relationship. In fact, it was possible to sort the points in the layers in such a way that it was possible, for the first time, to "turn off" those layers of existing buildings that "made noise", in order to understand the whole. An example of this can be seen in Figure 12.

In this way, the exact models and virtualizations of the vestiges that still remained from each era were achieved in their precise context and in relation to the environment, resulting in the virtualization of the possible bastion existing at this point, as shown in Figure 13. The bastion or entrance to the wall that, until now, not only was not known of, but it was taken for granted that it was otherwise. This knowledge served to declare this section a Property of Cultural Interest (BIC), establishing a protection that would otherwise have been impossible to achieve. 


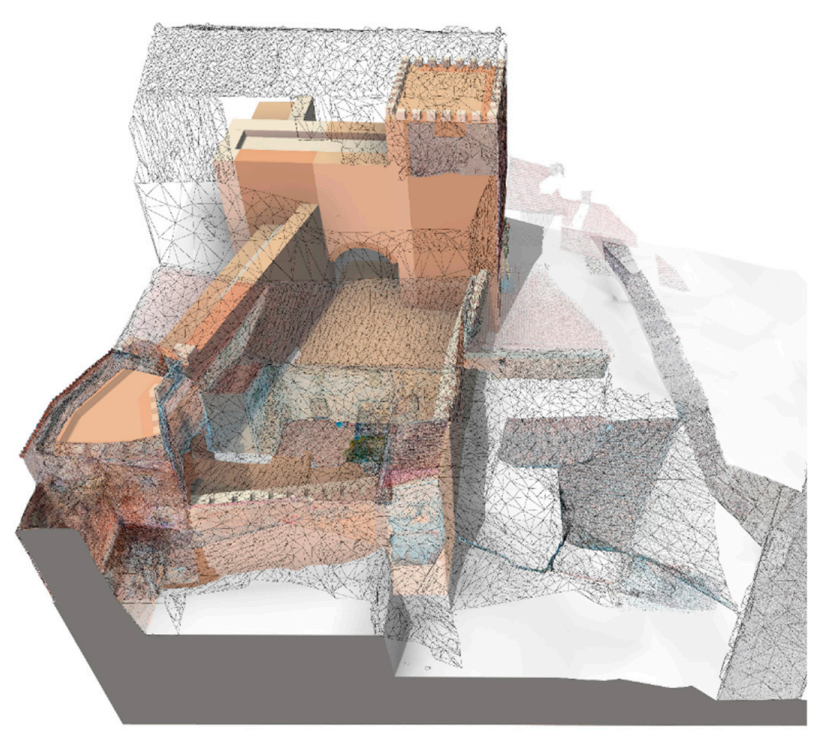

Figure 12. Modeling and digital documentation work. Concept of a possible bastion located between the Torre del Aire and the corrala to which our building allows access. The recreation is modeled in Revit, IFC format, from laser scanner shots that guarantee centimeter accuracy, which allows us to analyze reality.

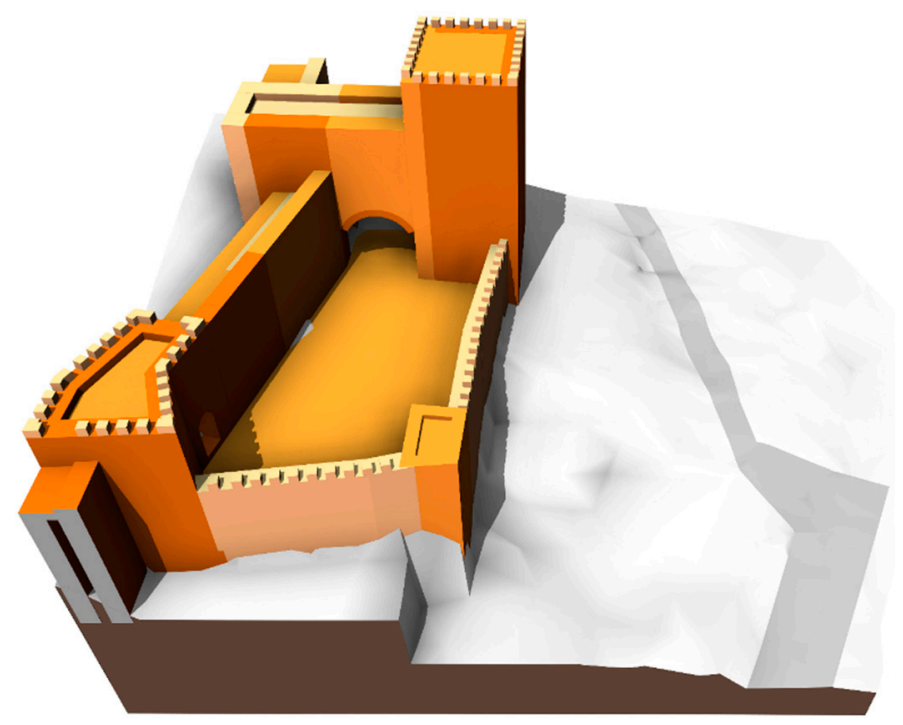

Figure 13. Virtual recreation of the hypothesis proposed in the studied area executed in IFC in a collaborative way.

Finally, we clarified that the geometric, material, and constructive conclusions that were reached after the completion of this investigation served to recover the property with a historical document treatment. This meant integrating the different stages found and dated during the study, from the beginning of its construction in the past. First, as a wall, which meant recovering its functionality, but without its materiality if it was no longer present, as was the case. That is, to force the design to recover the "feeling" of the old canvas, recreating the defensive element in its function, dimension, volumes, heights, etc., in order to know and feel how this flank of the city was defended, but not rebuilding the wall of the 13th century with its original materials. Second, as a popular residence in those rooms, which the most recent analysis and research date, which implies not modifying either the original distribution of the dependencies of the house or the composition of the holes in the facades. 
The small rooms in their irregularity and the anarchic and heterogeneous composition of the small doors and windows not only testify to what was a popular residence before today, but also recreate the "feeling" of living in it. Thanks to the research carried out, the intervention in this property shows that, all together, the wall as an origin and the popular residence as a destination, are the example of a living and evolving architecture over seven centuries, which allows us to talk about the evolution of society, the intramuros historic center, and the city from the past to the present.

Without all this research, not only the wall and its surroundings would remain great strangers in this particular area; all of the information about the real estate cataloging and local regulations referring to this area would remain incorrect, but also, in particular, this property, which is the only real and palpable vestige that remains of a bastion of the wall, would have disappeared. However, with the current project, it is intended that the visitor through the restoration of space could feel a living and evolutionary architecture of seven centuries, namely: to feel the space that had become a fortress, to feel the wall that was part of this fortress, to feel the city that followed the fortress, to feel the house in which the wall was transformed, and finally to feel the neighborhood to which the house contributed.

Author Contributions: P.A.C.F. conceived and designed the research. A.R.M.d.1.P. carried out the research and analysis of the results of the geometric model and of the pre-dimension considerations. P.A.C.F. conceived and carried out the research regarding the construction materials used in the models and methodology. All of the remaining parts were written, researched, and analyzed equally by A.R.M.d.l.P. and P.A.C.F. All of the main text was written by J.C.F. Software, P.A.C.F.; Supervision, J.C.F.; Visualization, A.R.M.d.l.P. All authors have read and agreed to the published version of the manuscript.

Funding: This research received no external funding.

Acknowledgments: The broadcasting of this work was possible thanks to the funding granted by the European Regional Development Fund (ERDF/FEDER) and the Junta de Extremadura to the research group COMPHAS through the aid (reference GR18032); Javier Mirabel and Jaime Ruiz for their collaboration in outdoor and office work; Raúl Clemente Asensio for the photographic documentation provided at the end of the construction of the Adarve del Cristo street number 7; Juan Pedro Cortés Pérez for his contribution in the structural calculation of the Adarve del Cristo street building project number 7; Juan Manuel Honrado and Fátima Gibello for their generosity and attention for data collection from their homes; Association of Neighbors of the Monumental Zone for their interest and support for the research topic; and Víctor Gibello for his brilliant archaeological work, not only of the property, but of the global environment of the wall.

Conflicts of Interest: The authors declare no conflict of interest.

\section{References}

1. Cruz Franco, J.; Cruz Franco, P.; de la Plata, A.R.M.; Ramos Rubio, J.; de San Pedro, J.R.M. Evolución histórica de la muralla de Cáceres y nuevos descubrimientos. El postigo de San Miguel, un lienzo perdido de la cerca almohade. Rev. Estud. Extrem. 2016, 72, 1869-1910.

2. Rodríguez González, A.; Martín Pulido, C. Proyecto para Reparar y Fortificar la Muralla de Cáceres en 1837; Trujillo, Spain, 2014; ISBN 978-84-697-1145-3. Available online: https:/dialnet.unirioja.es/servlet/libro? codigo $=565934$ (accessed on 20 August 2020).

3. Bravo Gibello, V. Informe de Catas Arqueológicas Murarias en Vivienda Situada en Adarve del Cristo, Author's Private File; Posted in academy.edu; Cáceres, Spain, 2017; Available online: https://www.academia.edu/43747350/Conclusiones_relativas_al_informe_de_catas_arqueol\%C3\% B3gicas_murarias_en_vivienda_situada_en_Adarve_del_Cristo_7_(accessed on 20 August 2020).

4. De la Plata, A.R.M.; Franco, P.A.C. A simulation study to calculate a structure conceived by Eugène Viollet-le-Duc in 1850 with finite element analysis. Materials 2019, 12, 2576. [CrossRef] [PubMed]

5. de La Plata, A.R.M.; Franco, P.A.C. Constructive and Graphic Study of the Influence of New Engineering Techniques in the Method, Theory and Design of Architecture between 1840 and 1872. In Proceedings of the Procedia Engineering; Elsevier Ltd.: Amsterdam, The Netherlands, 2016; Volume 161, pp. 1440-1444.

6. Chen, S.; Wang, S.; Li, C.; Hu, Q.; Yang, H. A seismic capacity evaluation approach for architectural heritage using finite element analysis of three-dimensional model: A case study of the limestone hall in the ming dynasty. Remote Sens. 2018, 10, 963. [CrossRef] 
7. Wilkinson, M.W.; Jones, R.R.; Woods, C.E.; Gilment, S.R.; McCaffrey, K.J.W.; Kokkalas, S.; Long, J.J. A comparison of terrestrial laser scanning and structure-frommotion photogrammetry as methods for digital outcrop acquisition. Geosphere 2016, 12, 1865-1880. [CrossRef]

8. Teza, G.; Pesci, A.; Ninfo, A. Morphological Analysis for Architectural Applications: Comparison between Laser Scanning and Photogrammetry, Structure-from-motion. J. Surv. Eng. 2016, 142, 04016004. [CrossRef]

9. Balletti, C.; Guerra, F.; Scocca, V.; Gottardi, C. 3D integrated methodologies for the documentation and the virtual reconstruction of an archaeological site. Int. Arch. Photogramm. Remote Sens. Spat. Inf. Sci. ISPRS Arch. 2015, 40, 215-222. [CrossRef]

10. Chen, S.; Hu, Q.; Wang, S.; Yang, H. A virtual restoration approach for ancient plank road using mechanical analysis with precision 3D data of heritage site. Remote Sens. 2016, 8, 828. [CrossRef]

11. Remondino, F. Heritage recording and 3D modeling with photogrammetry and 3D scanning. Remote Sens. 2011, 3, 1104-1138. [CrossRef]

12. Barazzetti, L.; Banfi, F.; Brumana, R.; Gusmeroli, G.; Previtali, M.; Schiantarelli, G. Cloud-to-BIM-to-FEM: Structural simulation with accurate historic BIM from laser scans. Simul. Model. Pract. Theory 2015, 57, 71-87. [CrossRef]

13. Balsa-Barreiro, J.; Fritsch, D. Generation of visually aesthetic and detailed 3D models of historical cities by using laser scanning and digital photogrammetry. Digit. Appl. Archaeol. Cult. Herit. 2017, 8, 57-64. [CrossRef]

14. Guarnieri, A.; Fissore, F.; Masiero, A.; Vettore, A. From TLS survey to 3d solid modeling for documentation of built heritage: The case study of porta savonarola in Padua. Int. Arch. Photogramm. Remote Sens. Spat. Inf. Sci. ISPRS Arch. 2017, 42, 303-308. [CrossRef]

15. González Moreno-Navarro, A. La Restauración Objetiva (Método SCCM de Restauración Monumental). Memoria SPAL 1993-1998; Diputacio de Barcelona: Barcelona, Spain, 1999.

16. Chiabrando, F.; Spanò, A.; Sammartano, G.; Losè, L.T. UAV oblique photogrammetry and LiDAR data acquisition for 3D documentation of the Hercules Fountain. Virtual Archaeol. Rev. 2017, 8, 83-96. [CrossRef]

17. Bertocci, S.; Pancani, G.; Cottini, A. The City Wall of Lastra a Signa: Integrated Digital Survey Methodologie; Defensive Architecture of Mediterranean; University of Granada: Granada, Spain, 2020; pp. 255-262.

18. Zazo, A.; Jiménez, D.; Farjas, M. Visual Guide of Trimble RealWorks ${ }^{\circledR}$, La Esgástula. Madrid, Spain. 2011. Available online: https://www.abebooks.co.uk/9788493849016/Gu\%C3\%ADa-visual-Trimble-Realworkssoftware-8493849014/plp (accessed on 20 August 2020).

19. Bedford, J. Historic England Photogrammetric Applications for Cultural Heritage; HISTORIC ENGLAND: London, UK, 2017.

20. Agisoft LLC. Agisoft Metashape User Manual; Agisoft LLC: Saint Petersburg, Russia, 2019.

21. Bassier, M.; Vincke, S.; De Lima-Hernandez, R.; Vergauwen, M. An overview of innovative heritage deliverables based on remote sensing techniques. Remote Sens. 2018, 10, 1607. [CrossRef]

22. Chiabrando, F.; Donadio, E.; Rinaudo, F. SfM for orthophoto generation: Awinning approach for cultural heritage knowledge. Int. Arch. Photogramm. Remote Sens. Spat. Inf. Sci. ISPRS Arch. 2015, 40, 91-98. [CrossRef]

23. Bechtel, T.; Truskavetsky, S.; Pochanin, G.; Capineri, L.; Sherstyuk, A.; Viatkin, K.; Byndych, T.; Ruban, V.; Varyanitza-Roschupkina, L.; Orlenko, O.; et al. Characterization of electromagnetic properties of in situ soils for the design of landmine detection sensors: Application in Donbass, Ukraine. Remote Sens. 2019, 11, 1232. [CrossRef]

24. Park, B.; Kim, J.; Lee, J.; Kang, M.S.; An, Y.K. Underground object classification for urban roads using instantaneous phase analysis of ground-penetrating radar (GPR) data. Remote Sens. 2018, 10, 1417. [CrossRef]

25. De la Plata, A.R.M.; Pérez del Rio, L.M.; Cruz Franco, P.A. Propuesta de metodología no invasiva para la caracterización constructiva y geométrica de depósitos de agua y aljibes en edificaciones histórico artísticas. In Proceedings of the Construction Pathology, Rehabilitation Technology and Heritage Management, Caceres, Spain, 15-18 May 2018; pp. 925-933.

26. Ayala-Cabrera, D.; Herrera, M.; Izquierdo, J.; Perez-Garcia, R. Location of buried plastic pipes using multi-agent support based on GPR images. J. Appl. Geophys. 2011, 75, 679-686. [CrossRef]

27. Parrinello, S.; Galasso, F.; Picchio, F.; Miceli, A.; De Marco, R.; La Placa, S.; Dell'Amico, A.; Doria, E. Procedure di analisi e modellazione urbana per la gestione dei centri storici. Betlemme, Solikamsk, Cattaro e Santo Domingo. Paesaggio Urbano 2020, 2, 103-115. 
28. Miceli, A.; Morandotti, M.; Parrinello, S. 3D survey and semantic analysis for the documentation of built heritage. The case study of Palazzo Centrale of Pavia University. Int. Lournal Archit. Technol. Sustain. 2020, 5, 65. [CrossRef]

29. Cozzolino, M.; Gentile, V.; Mauriello, P.; Peditrou, A. Non-Destructive Techniques for Building Evaluation in Urban Areas: The Case Study of the Redesigning Project of Eleftheria Square (Nicosia, Cyprus). Appl. Sci. 2020, 10, 4296. [CrossRef] 